\title{
Atom Probe Tomography Analyses of Solute Segregation in Self-Ion Irradiated Electron-Beam Welded SA508 Grade 3 Reactor Pressure Vessel Steels
}

\author{
J. O. Douglas ${ }^{1 *}$, P. A. J Bagot ${ }^{1}$, M. G. Burke ${ }^{2}$, M. P. Moody ${ }^{1}$ \\ 1. Department of Materials, University of Oxford, Parks Road, Oxford OX1 3PH, UK. \\ 2. School of Materials, University of Manchester, The Mill, Manchester M11 9PL, UK. \\ * Corresponding author: james.douglas@materials.ox.ac.uk
}

Reactor Pressure Vessels (RPVs) are safety-critical components of light water reactors and are subjected to long-term neutron irradiation at elevated temperatures during service, promoting microstructural changes that can reduce the toughness of steels, particularly welds [1]. Nanoscale solute segregation leading to the formation of solute-enriched clusters enriched in $\mathrm{Ni}, \mathrm{Mn}, \mathrm{Si}$ and $\mathrm{Cu}$ have been identified using high resolution nanoscale microscopy techniques such as Atom Probe Field-Ion Microscopy [2] and Atom Probe Tomography (APT) [3], as well as Field Emission Gun-Scanning Transmission Electron Microscopy Electron Energy Dispersive Spectroscopy (FEG-STEM EDXS) techniques [4]. These solute-enriched clusters are associated with increased hardness, and with increases in the ductileto-brittle transition temperature.

Conventional vessel fabrication requires metal joining techniques such as Submerged Arc Welding (SAW) that use a filler metal with a different composition to the bulk, thereby adding another variable to the microstructural evolution in the welded section. Weld regions are always of concern as they can be areas of potential mechanical failure [5]. Electron beam (EB) welding is an autogenous process (no filler metal is required) that allows two pieces of steel to be joined directly, removing issues associated with filler metal composition. However, this process still results in microstructural variation from the base metal and the heat-affected zone (HAZ) into the Fusion Zone. EB welding is generally applied for welds $\sim \mathrm{cm}$ thick, and has potential applications in smaller, modular structures [5]. The purpose of this study was to explore nanoscale solute clustering resulting from ion irradiation of EB welded steels to assess similarities and differences between EB and conventional SAW microstructures reported in the literature.

SA508 Gr3 forging steel sections (30 mm in thickness) were EB-welded and sectioned. Specimens were obtained in the as-welded (AW) and Stress-Relieved (SR) $\left(\sim 600^{\circ} \mathrm{C}\right.$ for $\sim 1$ hour $)$ conditions. Self ionirradiation (SII) $\left(5 \mathrm{MeV}, 300{ }^{\circ} \mathrm{C}, \mathrm{Fe}^{4+}\right)$ was then performed on $3 \mathrm{~mm}$-diameter discs taken from the SRHAZ, with doses calculated to give a range between $0.3 \mathrm{dpa}$ at $200 \mathrm{~nm}$ depth and $1.25 \mathrm{dpa}$ at $1.25 \mu \mathrm{m}$ depth (Figure 1 - right). APT analyses were performed on the base materials and AW-HAZ, SR-HAZ and SII-SR-HAZ samples extracted using site-specific Focused Ion Beam (FIB) liftout techniques such that the APT analysis volumes were located within the irradiated layer in order to assess changes in irradiation response with dose (Figure 1 - left). These samples were analysed using optimized conditions for quantitative analysis of solute segregation in RPV steels and cluster analysis was performed using the maximum separation method [6].

AW-HAZ and SR-HAZ samples were observed to have increased numbers of dislocations compared to the base metal, as expected, with APT analysis showing low levels of segregation of $\mathrm{C}$ to dislocations in the AW-HAZ. More pronounced segregation of Mo and $\mathrm{C}$ was observed on dislocation networks within the SR-HAZ (Figure 2 - left). Al/Si/N enriched features and Mn enriched features were also found 
spatially segregated to these dislocation networks in the SR-HAZ.

After irradiation, increased levels of solute (particularly Mn) were observed to segregate to dislocations and $\mathrm{Mo} / \mathrm{C} / \mathrm{Al}$ rich features in the SII-SR-HAZ samples (Figure 2 - right) whilst relatively few homogeneously nucleated nanoscale solute-enriched clusters were observed away from these features. This indicates that the dislocation networks are acting as preferential heterogeneous segregation sites for solute, altering the location of solute such as Mn prior to irradiation and thus altering the irradiation response in terms of clustering behavior during irradiation in agreement with [4]. J. O. Douglas was funded by EPSRC Grant No.EP/P005101/1 [7].

\section{References:}

[1] G. R. Odette and G. E. Lucas, JOM 53 (2001), p. 18-22.

[2] M.G. Burke and S.S. Brenner, J. de Physique, 34:C2 (1986) p. 239-243

[3] M. K. Miller et al, Journal of Nuclear Materials 437 (2013), p. 107-115.

[4] M.G. Burke et al., J. Mat. Sci. 41(2006) p. 4512-4522.

[5] J. Balakrishnan et al, International Journal of Pressure Vessels and Piping 162 (2018), p. 59-70.

[6] P. D. Styman et al, Ultramicroscopy 132 (2013), p. 258-264.

[7] The authors acknowledge funding from EPSRC Grant No.EP/P005101/1.
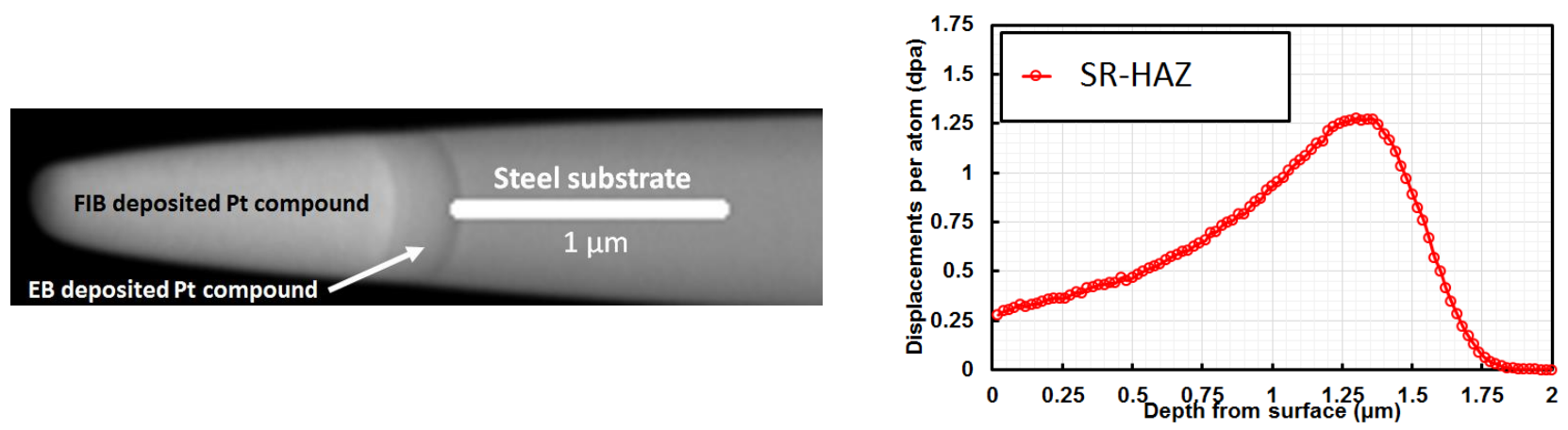

Figure 1. SEM micrograph of atom probe sample prior to final low $\mathrm{kV} \mathrm{Ga}^{+}$polishing stage (left). Stopping and Range of Ions in Matter modelling showing dpa vs depth for the SII samples (right).


Figure 2. Atom map showing 2 at.\% iso-concentration surface of Mo, indicating dislocation in SRHAZ sample (left). Atom map of SII-SR-HAZ ( $\sim 0.5 \mathrm{dpa})$ containing Mo/Al rich enriched regions, with segregation of $\mathrm{Mn} / \mathrm{Ni}$ to entire enriched region and segregation of $\mathrm{Si}$ to $\mathrm{Al}$ enriched side (right). 